OPEN ACCESS

ISSN 2338-445X (online) ISSN 2527-9246 (print)

Edited by:

Ilmi Usrotin Choiriyah

Reviewedby:

Ismi Dwi Astuti Nurhaeni and Bambang Kusbandrijo

${ }^{\star}$ Correspondence:

Mashudi

emashud@lecturer.undip.ac.id

Published:29 Maret 2021

Citation:

Mashudi (2021) LOGISTIC

BUSINESS POLICY AND

STRATEGY: Women's

Opportunities and Participation

in the Warehouse Industry.

JKMP(Jurnal Kebijakan dan

Manajemen Publik). 9:1.

doi: $10.21070 / j k m p . v 9 i 1.1565$

\section{Logistic Business Policy And Strategy: Women's Opportunities And Participation In The Warehouse Industry}

\author{
Kebijakan Dan Strategi Bisnis Logistik : Peluang Dan \\ Partisipasi Perempuan Dalam Warehouse Industry
}

Mashudi*, Luluk Fauziah, Johan Bhimo Sukoco, Anafil Windriya, Vina Septiana Eka Sari

Universitas Diponegoro Semarang, Indonesia

\section{ABSTRACT}

Departing from a condition in which the number of women involved in the warehouse sector industry is still low, even though culture in Indonesia does not hinder their involvement, there are opportunities to participate, and the existence or existence of women in this industry is not contradictory, so this study aims to determine how high the level of women's participation in the warehouse sector industry, as well as to find out what factors influence their involvement.

This study uses a quantitative approach with an explanatory and survey research format. Data was collected by distributing questionnaires to 70 respondents who were determined purposively. In addition, interviews were also conducted with several respondents as well as documentation and observation techniques. Data processing was carried out using percentage techniques and multiple linear regression techniques with the help of the SPSS (Statistical Program for the Social Science) program.

The results of this study are as follows: 1) women's participation in the warehouse sector industry is still at a low level; 2) culture, existence and opportunities have an effect either partially or simultaneously on women's participation; 3) while the opportunity variable has the most significant effect on women's participation; 4) there are a small number of other variables that are not involved in this study which also influence women's participation in the warehouse sector industry.

Keywords: culture, existence, opportunity, and participation

\section{PENDAHULUAN}

Industri logistik khusunya di sektor gudang yang tergabung dalam ALFI (Asosiasi Logistik/ Forwarder Indonesia) yang mencakup wilayah Jawa Tengah dan Daerah Istimewa Yogyakarta sejumlah 20 perusahaan. Dengan jumlah pegawai seluruhnya 480 orang yang terrinci sejumlah 365 orang laki-laki dan 115 orang perempuan. Demikian keberadaan perempuan dalam industri gudang sebesar $23 \%$. 
Jumlah penduduk Jawa Tengah sebesar 36.520.000 jiwa (Jateng Dalam Angka) sedangkan jumlah penduduk DIY sebesar 3.842.932 jiwa (DIY Dalam Angka). Jika ditotal, jumlah penduduk Jateng dan DIY yang berjenis kelamin laki-laki sebesar 20.261.735 jiwa $(50,20 \%)$ sedangkan yang berjenis perempuan sebesar 20.091.197 jiwa (49.80\%). Dengan mengamati sebaran data tersebut di atas, dapat disimpulkan bahwa jumlah penduduk yang berjenis laki-laki dan berjenis perempuan berbeda tipis. Di industri sektor gudang, jumlah pegawai laki-laki berjumlah 365 orang dan pegawai perempuan berjumlah 115 orang. Ini berarti partisipasi atau peran perempuan dalam industri ini jauh lebih kecil dibanding lakilaki. Maka penelitian ini bertujuan untuk mengetahui faktor-faktor apa saja yang mempengaruhi kecilnya keterlibatan perempuan dalam industri sektor Gudang.

Budaya menurut Geert Hofstede (Senior, 2002) menyatakan bahwa budaya merupakan sekumpulan pikiran manusia yang dipergunakan untuk membedakan antara manusia yang satu dengan yang lain dalam suatu kelompok. Budaya dalam pengertian ini, menurut Hofstede merupakan sebuah sistem nilai yang dipatuhi bersama. Menurut (Berger, Peter, 1992), bahwa kebudyaan ialah "totalitas dari produk manusia. Tidak hanya mencakup produk material atau material artefacts dan produk non-material sosio-kultural, akan tetapi juga produk refleksi di dalam isi kesadaran manusia".

Penelitian ini mengacu pada pengertian kebudayaan sebagai keseluruhan pengetahuan manusia yang dijadikan sebagai pedoman atau penginterpretasi keseluruhan tindakan manusia. Kebudayaan adalah pedoman bagi kehidupan masyarakat yang diyakini kebenarannya oleh masyarakat tersebut (Suparlan, 1994).

Berdasarkandefinisi kebudayaan sebagaimana tersebut di atas, akan memungkinkan perempuan berberan dan eksis di industri sektor gudang dapat dikaji, sebab tindakantindakan yang diciptakan perempuan untuk mencapai kinerjanya merupakan model-model pengetahuan yang secara selektif digunakan untuk menginterpretasi lingkungan yang dihadapi.

Eksistensin berasal dari kata exist. Kata exist berasal dari kata ex, yang artinya keluar dan sister, yang berarti keluar. Jadi eksistensi berdiri dengan keluar dari diri sendiri (Maksum, 2008). Pada umumnya kata eksistensi dimaknai keberadaan. Eksistensi adalah cara manusia berada di dunia yang berbeda dengan cara benda-benda yang juga berada di dunia. Bendabenda tidak sadar akan keberadaannya, tidak ada hubungannya antara benda yang satu dengan benda yang lainnya meskipun benda-benda itu berdampingan, sedangkan manusia sadar akan keberadaannya dan ada hubungannya dengan manusia yang ada disampingnya.

Secara etimologi, kata eksistensi berasal dari Bahasa Latin yaitu dari kata existere. Kata existere berasal dari kata ex yang berarti keluar dan sistere yang berarti tampul atau muncul. Esistensi berarti ada, muncul, atau memiliki kebaradaan aktual (Bagus, 2005). Peluang menurut (Kotler, P dan Amstrong, 2008), adalah faktor atau tren yang menguntungkan pada lingkungan eksternal yang dapat digunakan perusahaan untuk memperoleh keuntungan. Sedangkan menurut (Fred, 2015), peluang adalah situasi penting yang menguntungkan dalam lingkungan perusahaan. Situasi yang menguntungkan ini bisa berupa perkembangan teknologi, perubahan perilaku konsumen, dan faktor eksternal lainnya. Selanjutnya pendapat tersebut di atas, maka dapat disimpulkan bahwa peluang adalah lingkungan eksternal yang berpotensi memberi keuntungan bagi seseorang atau organisasi untuk berperan maupun untuk memperoleh keberhasilan.

Berdasarkan uraian di atas, maka dapat dirumuskan pertanyaan penelitian sebagai berikut : 1) Pada tingkat manakah partisipasi perempuan dalam industri gudang/ warehouse ?; 2) Apakah variabel budaya, eksistensi dan peluang berpengaruh secara parsial terhadap partisipasi perempuan ?; 3) Apakah variabel budaya, eksistensi dan peluang berpengaruh secara simultan terhadap partisipasi perempuan ?; dan 4) Manakah diantara variabel budaya, eksistensi dan peluang yang pengaruhnya paling signifikan terhadap partisipasi perempuan ?. 


\section{METODE PENELITIAN}

Pendekatan yang digunakan dalam penelitian ini adalah pendekatan kuantitatif dan menggunakan format penelitian eksplanasi dan survey. Penelitian eksplanasi adalah sebuah penelitian yang beranggapan bahwa suatu fenomena atau peristiwa terjadi pasti ada penyebabnya, sehingga penelitian eksplanasi adalah penelitian yang mampu menjelaskan mengapa fenomena terjadi (Sarwono, 2006). Cakupan penelitian ini adalah seluruh perusahaan yang bergerak dalam industri sektor gudang yang tergabung dalam ALFI (Asosiasi Logistik/ Forwarder Indonesia) meliputi wilayah Jawa Tengah dan Daerah Istimewa Yogyakarta sejumlah 20 perusahaan. Adapun jumlah pegawai seluruhnya 480 orang dengan rincian 365 laki-laki dan 115 perempuan.

Variabel yang terlibat dalam penelitian ini adalah variabel budaya (X1), eksistensi (X2), peluang (X3), dan variabel partisipasi( Y). Populasi dalam penelitian ini berjumlah 115 orang pegawai perempuan dan diambil sebagai sampel sebesar 70 orang pegawai sebagai responden dengan teknik purposive. Pengumpulan data dilakukan dengan menyebarkan angket keseluruh anggota sampel. Dalam penelitian ini juga digunakan teknik pengumpulan data wawancara dengan tujuan untuk mengecek dan memperkaya data yang diperoleh dari angket, serta teknik dokumentasi untuk melengkapi data yang diperoleh dari wawancara dan angket serta dilakukan pula observasi guna mengetahui aktivitas pegawai di industri sektor gudang. Dalam rangka memenuhi persyaratan angket yang baik yaitu valid dan reliabel, maka sebelum angket disebarkan kepada responden yang sesungguhnya, di uji dulu validitas maupun reliabilitasnya. Sebelum data diolah lebih lanjut, dilakukan uji asumsi klasik yang meliputi uji normalitas, uji heteroskedastisitas, uji autokorelasi, dan uji multikolinearitas. Setelah dilakukan uji asumsi klasik dan hasil uji menyatakan memenuhi syarat untuk dilakukan analisis selanjutnya, maka berikutnya dilakukan analisis dengan teknik analisis regresi linier berganda. Dalam analisis data ini dibantu oleh program SPSS (Statistical Program for the Social Science).

\section{TEMUAN}

Dari hasil olahan data penelitian diperoleh informasi sebagai berikut :1) Data tersebar berada di sekitar garis diagonal. Dengan demikian dapat dinyatakan bahwa data terdistribusi normal. 2) Data tersebar dengan tidak membentuk pola-pola tertentu atau tidak ada pola yang jelas, serta titik-titik menyebar di atas dan dibawaha ngka 0 pada sumbu Y atau sumbu vertikal, maka model regresi bersifat homogen. Dengan demikian dapat dinyatakan bahwa dalam data ini tidak terdapat problem heteroskedastisitas. 3) Nilai Durbin-Watson sebesar 2,141 (berada diantara -2 dan +3$)$, dengan demikian dapat dinyatakan bahwa dalam data ini tidak terjadi problem autokerasi. 4) Nilai VIF(Variance Inflatio Factor) untuk masing-masing variabel sebagai berikut : budaya (X1) sebesar 5,48; eksistensi (X2) sebesar 6,744, peluang (X3) sebesar5,035. Karena nilai VIF lebih kecil dari $10(<10)$, ini memberi indikasi bahwa tidak terdapat problem multikolinearitas.

Dari hasil olahan data penelitian diperoleh informasi sebagai berikut :

Jumlah pegawai di industri di sektor gudangs ebesar 480 orang, yang terdiri dari 365 orang laki-laki dan 115 orang perempuan. Dilihat dari prosentasenya, jumlah pegawai perempuan sebesar 23\%, ini mengidikasikan bahwa partisipasi perempuan dalam industri sektor gudang masih rendah.

Nilai signifikan simasing-masing variabel sebagai berikut : budaya (X1) sebesar 0,015; eksistensi (X2) sebesar 0,004, peluang (X3) sebesar 0,011. Karena seluruh nilai signifikasi lebih kecil dari $0,050(<0,050)$, ini memberi indikasi bahwa masing-masing variabel berpengaruh secara parsial terhadap variabel partisipasi. Dengan demikian ada alasan yang kuat untuk menolak $\mathrm{H} 0$ dan menerima $\mathrm{H} 1$ yang menyatakan"ada pengaruh variabel budaya, eksistensi, dan peluang secara parsial terhadap partisipasi perempuan dalam industri sektor gudang". 
Selain itu diperoleh informasi pula bahwa variabel eksistensi berpengaruh paling siginifkan, disusul secara berturut-turut variabel peluang dan berikutnya variabel budaya. Hal ini diperkuat dengan temuan berupa besarnya nilai t hitung pada masing-masing variabel sebagai berikut : budaya (X1) sebesar 2,487; eksistensi (X2) sebesar 2,991, peluang (X3) sebesar 2,632. Nilai t hitung paling besar adalah variabel eksistensi, berikutnya peluang, dan yang paling kecil adalah variabel budaya. Dengan demikian ada alasan yang kuat untuk menolak H0 dan menerima H1 yang menyatakan"diantara variabel budaya, eksistensi, dan peluang: variabel eksistensi berpengaruh paling signifikan terhadap partisipasi perempuan dalam industri sektor gudang".

Nilai F hitung sebesar 0,000. Karena nilai F hitung lebih kecil dari 0,050 $(<0,050)$, ini memberi indikasi bahwa variabel bebas yang terdiri dari tiga variabel tadi berpengaruh secara simultan terhadap variabel terikat yaitu variabel partisipasi. Dengan demikian ada alasan yang kuat untuk menolak $\mathrm{HO}$ dan menerima $\mathrm{H} 1$ yang menyatakan"ada pengaruh variabel budaya, eksistensi, dan peluang secara simultan terhadap partisipasi perempuan dalam industri sektor gudang".

Besarnya nilai $\mathrm{R}$ Square adalah 0,841 atau sebesar $84,10 \%$. Ini berarti bahwa variabel bebas berkontribusi terhadap variabel terikat sebesar $84,10 \%$. Dengan demikian dapat disimpulkan masih terdapat pengaruh dari variabel lain yang tidak terlibat dalam penelitian ini sebesar $15,90 \%$.

\section{HASIL DAN PEMBAHASAN}

Hasil pengujian hipotesis menunjukkan bahwa budaya berpengaruh bermakna terhadap partisipasi perempuan dalam idustri sektor gudang. Hal ini ditunjukan oleh hasil olahan data yaitu nilai signifikan sebesar 0,015, lebih kecil dari 0,050 $(<0,050)$.

Luaran penelitian ini sesuai dengan hasil penelitian (Mashudi, 2015), yang menyatakan bahwa makin kuat dimensi budaya, makin tinggi tingkat perilaku produktif. Perilaku produktif bisa diterapkan diberbagai kegiatan termasuk di dalam melaksanakan kegiatan mata pencaharian yang berupa sebagai pegawai pada industri sektor gudang. Perilaku produktif selanjutnya berdampak pada peningkatan pendapatan rumah tangga. Luaran penelitian ini juga relevan dengan teori unsur-unsur budaya yang dikemukakan oleh (Koentjaraningrat, 2004) yang salah satu unsur budaya berupa sistem mata pencaharian. Menurut Koentjaraningrat, unsur-unsur budaya meliputi : 1) Sistem religi dan upacara keagamaan; 2) Sistem dan organisasi kemasyarakatan; 3) Sistem pengetahuan; 4) Bahasa; 5) Kesenian; 6) Sistem mata pencaharian; dan 7) Teknologi dan pertanian.

Dengan demikian dapat diyatakan bahwa kajian ini terbukti menunjukkan bahwa budaya berpengaruh secara signifikan terhadap partisipasi perempuan dalam industri sektor gudang. Semakin tinggi nilai budaya, semakin tinggi pula partisipasi perempuan dalam industri sektor gudang. Sebaliknya, semakin rendah nilai budaya, semakin rendah pula partisipasi perempuan dalam industri sektor gudang.

Luaran penelitian ini yang menyatakan bahwa budaya berpengaruh secara sigifikan terhadap partisipasi perempuan dalam industri sektor gudang, namun nilai signifikansinya paling rendah dibanding nilai signifikansi variabel-variabel yang lain. Dengan demikian luaran penelitin ini relevan dengan tingkat partisipasi perempuan dalam industri sektor gudang, yaitu hanya sebesar $23 \%$, ini mengidikasikan bahwa partisipasi perempuan dalam industri sektor gudang masih rendah.

Hasil pengujian hipotesis menunjukkan bahwa eksistensi berpengaruh bermakna terhadap partisipasi perempuan dalam idustri sektor gudang. Hal ini ditunjukan oleh hasil olahan data yaitu nilai signifikansi sebesar 0,004, lebih kecil dari 0,050 $(<0,050)$.

Luaran penelitian ini sesuai dengan hasil penelitian Marlina (2015), yang menyatakan bahwa pengembangan ekonomi lokal/ local economic development (LED) tidak terlepas dari keberadaan dan peran serta masyarakat yang ingin memaksimalkan potensi lokalnya 
Dengan demikian dapat diyatakan bahwa kajian ini terbukti menunjukkan bahwa eksistensi berpengaruh secara signifikan terhadap partisipasi perempuan dalam industri sektor gudang. Semakin tinggi nilai eksistensi, semakin tinggi pula partisipasi perempuan dalam industri sektor gudang. Sebaliknya, semakin rendah nilai eksistensi, semakin rendah pula partisipasi perempuan dalam industri sektor gudang.

Hasil pengujian hipotesis menunjukkan bahwa peluang berpengaruh bermakna terhadap partisipasi perempuan dalam industri sektor gudang. Hal ini ditunjukan oleh hasil olahan data yaitu nilai signifikansi sebesar 0,011, lebih kecil dari0,050 $(<0,050)$.

Luaran penelitian ini sesuai dengan hasil penelitian (Syamruddin, 2018), yang menyatakan bahwa makin tinggi peluang sebuah produk terjual di pasar, maka makin tinggi tingkat jualnya. Luaran penelitian ini juga relevan dengan teori peluang yang dikemukakan oleh (Kotler, P dan Amstrong, 2008), bahwa peluang adalah faktor atau tren yang menguntungkan pada lingkungan eksternal yang dapat digunakan perusahaan untuk memperoleh keuntugan. Luaran penelitian ini sesuai dengan hasil penelitian (Hasibuan, 2020), yang menyatakan bahwa makin tinggi peluang di pasar tradisional, maka makin tinggi pendapatan pedagang di pasar tradisional. Luaran ini juga relevan dengan teori peluang yang dikemukakan oleh (Fred, 2015) yang menyatakan bahwa peluang adalah situasi penting yang menguntungkan dalam lingkungan perusahaan.

Dengan mencermati teori yang dikemukakan oleh Kotler dan Fred serta hasil penelitian dari Syamruddin maupun Hasibuan, dapat dinyatakan bahwa peluang adalah kondisi yang meguntungkan bagi semua pihak yang memperolehnya.

Dengan demikian dapat diyatakan bahwa kajian ini terbukti menunjukkan bahwa peluang berpengaruh secara signifikan terhadap partisipasi perempuan dalam industri sektor gudang. Semakin tinggi peluang, semakin tinggi pula partisipasi perempuan dalam industri sektor gudang. Sebaliknya, semakin rendah peluang, semakin rendah pula partisipasi perempuan dalam industri sektor gudang.

Kebijakan menurut (Dye, 1992) yang menyatakan bahwa "Anything a government chooses to do or not to do", kebijakan publik adalah segala sesuatu yang dikerjakan atau tidak dikerjakan oleh pemerintah. Mencermati teori kebijakan tersebut, dalam implementasinya pemerintah menerapkan kebijakan dengan membiarkan perempuan berpartisipasi dalam indusrti sektor Gudang, demikian pula pelaku bisnis juga menerapkan strategi dengan membiarkan partisipasi perempuan untuk masuk di dalam industri sektor Gudang. Namun demikian kenyataan dilapangan menunjukkan bahwa partisipasi perempuan masih tergolong rendah (23\%). Padahal seluruh variable bebas yang terdiri dari budaya, eksistensi, dan peluang berpengaruh secara signifikan terhadap partisipasi perempuan pada industri sektor gudang. Mengapa demikian, jika seumpam adalam variabel bebas disertakan variabel lingkungan kerja, hasilnya akan berbeda dengan 3 (tiga) variabel sebelumnya, hal ini kenapa terjadi, sangat mungkin dikarenakan situasi lingkungan pekerjaan di industri sektor Gudang kurang atau tidak menarik bagi perempuan. Karena kenyataanya, pekerjaan industri di sektor gudang tidak sepenuhnya berupa pekerjaan administratif dan kantoran yang itu semua menarik bagi perempuan. 


\section{KESIMPULAN}

Kesimpulan penelitian ini sebagai berikut : 1) partisipasi perempuan dalam industri sektor gudang masih berada pada tingkat rendah; 2) budaya, eksistensi dan peluang berpengaruh baik secara parsial maupun simultan terhadap partisipasi perempuan; 3) sedangkan variabel peluang berpengaruh paling signifikan terhadap partisipasi perempuan; 4) terdapat sebagian kecil variabel lain yang tidak terlibat dalam penelitian ini yang ikut mempengaruhi partisipasi perempuan dalam industri sektor gudang. Maka disarankan bagi pen eliti yang akan datang memasukkan variabel bebas selain budaya, eksistensi dan peluang.

\section{PENDANAAN}

Publikasi artikel ini menggunakan dana pribadi dari penulis.

\section{UCAPAN TERIMA KASIH}

Pertama-tama kami ucapkan terima kasih atas kepada civitas akademika Universitas Diponegoro atas dukungannya sehingga artikel kami dapat di publish di Jurnal Kebijakan dan Manajemen Publik. 


\section{REFERENCES}

Bagus, Lorens. 2005. Kamus Filsafat. Jakarta : Gramedia Pustaka Utama.

Berger, Peter, Brigette Berger dan Hansfried Kellner. 1992. Pikiran Kembara : Modernisasi dan Kesadaran Manusia. Yogyakarta : Kanisius.

Dye, Thomas R. 1992. Understanding Public Policy. New Jersey: Prentice Hall.

Fred, R. David. 2015. Manajemen Strategis. Jakarta : Salemba Empat.

Hasibuan, Siti Jubaidah. 2020. Analisis Potensi Pasar Tradisiona ldalam Meningkatkan Pendapatan Pedagang di Pasar Tradisional Keluarga Jalan HOS Cokroaminoto Kelurahan Simpang III Sipin Kota Jambi. Skrpsi Fakultas Ekonomi dan Bisnis Islam Universitas Islam Negeri Sulthan Thaha Saifuddin Jambi.

Kotler, P dan Armstrong, G. 2008. Prinsip-psinsip Pemasaran. Jakarta : Erlangga.

Koentjaraningrat, 2004. Bunga Rampai Kebudayaan, Mentalitas dan Pembangunan. Jakarta : PT Gramedia Pustaka Utama.

Mashudi, 2015. Antecedent Pendapatan Rumah Tangga Petani Tambak di Sidoarjo. Malang :Prosiding SENABISMA, Volume : 2, 8 Oktober 2015

Maksum, Ali. 2008. Pengantar Filsafat. Yogyakarta : ArRuszz Media.
Sarwono, J. 2006. Metode Penelitian Kuantitatif \& Kualitatif. Yogyakarta : Graha Ilmu

Senior, Barbara. 2002. Organisational Change (Second Edition). London : Financial Times Prentice Hall.

Suparlan, Parsudi. 1994. Kebudayaan dan Pembangunan dalam media IKA, No. 11, 1979/1980.

Syamruddin. 2018. Analisis Peluang dan Tantangan serta Prospek Bisnis PT Citra Karsa Integritas ditijau dari Aspek Bauran Pemasaran. Jurnal MADANI, Volume 1, Nomor2, September 2018).

Conflict of Interest Statement: The authors declare that the research was conducted in the absence of any commercial or financial relationships that could be construed as a potential conflict of interest.

Copyright (C) 2021 Mashudi et.al. This is an open-access article distributed under the terms of the Creative Commons Attribution License (CC BY). The use, distribution orreproduction in other forums is permitted, provided the original author(s) and the copyright owner(s) are credited and that the original publication in this journal is cited, in accordance with accepted academic practice. No use, distribution or reproduction is permitted which does not comply with these terms. 